\title{
Comparação do conhecimento tático processual em jogadores de futebol de diferentes categorias e posições
}

\author{
Diogo S. Giacomini \\ Pablo J. Greco
}

https://doi.org/10.5628/rpcd.08.01.126
Escola de Educação Física, Fisioterapia

e Terapia Ocupacional

Grupo de Estudos da Cognição e Ação

Universidade Federal de Minas Gerais

Brasil

\section{RESUMO}

O objetivo do presente estudo foi avaliar e comparar o nível de conhecimento tático processual de jogadores de Futebol de diferentes categorias e posições. A amostra deste estudo foi constituída por 221 jogadores de Futebol do sexo masculino. Para avaliar o conhecimento tático processual dos jogadores foi utilizado o teste KORA (Avaliação Orientada através do Conceito dos Peritos) desenvolvido por Memmert (2002), no parâmetro tático "Oferecer-se e Orientar-se". O nível de significância foi mantido em $p \leq 0,05$. A partir dos resultados encontrados, chegou-se às seguintes considerações: na comparação do conhecimento tático processual por categoria, tanto na manifestação do pensamento convergente quanto divergente, os jogadores da categoria sub-17 obtiveram melhores resultados em relação às categorias sub-15 e sub-14 $(\mathrm{p}<0,001)$. Já os jogadores da categoria sub-15, por sua vez, alcançaram melhores escores que os seus pares da categoria sub-14 ( $<<0,001)$. Ao considerar a posição específica dos jogadores, os goleiros apresentaram resultados significativamente diferentes de todas as outras posições, tanto no conhecimento tático processual convergente $(\mathrm{p}<0,001)$ quanto divergente $(\mathrm{p}<0,001)$. Já os meias também apresentaram resultados significativamente diferentes em relação aos zagueiros $(p=0,033)$ para o nível de conhecimento tático processual (divergente), demonstrando um maior nível de criatividade tática dos jogadores que jogam nessa posição.

Palavras-chave: futebol, conhecimento tático processual, criatividade tática

\section{ABSTRACT \\ Comparison of the procedural tactical knowledge in soccer play- ers of different categories and positions}

The main objective of this work was to validate and compare the level of procedural tactical knowledge of soccer players of different categories and positions. 221 male soccer players were part of this work. The KORA test (Oriented Validate through Expert Concepts) was used in order to validate the procedural tactical knowledge. This test was developed by Memmert (2002), in the tactical parameter of "Offer Yourself and Self-Orientation". Taking the results into account we can take into consideration the following aspects: comparing the procedural tactical knowledge per category, in the manifestation of the convergent and divergent thoughts, soccer players of the sub-17 category got better results in relation with the sub-14 category and the sub-15 category $(p<0,001)$. Sub-15 players got better scores than their peers from the sub-14 category $(p<0,001)$. When players got into groups according to specific field positions, goal keepers showed very different results from other positions, in convergent procedural tactical knowledge $(p<0,001)$ and divergent procedural tactical knowledge $(p<0,001)$. Already the middle-field players also had significantly different results on defenders $(p=0.033)$ for the level of tactical procedural knowledge (divergent), showing a higher level of tactical creativity of the players who play in that position.

Key-words: soccer, procedural tactical knowledge, tactical creativity 


\section{INTRODUÇÃO}

Ao deparar-se com alguns momentos mágicos proporcionados por atletas de elite, como por exemplo, o drible de Pelé contra o Uruguai (Copa do Mundo de 1970, no México), o gol de Maradona contra Inglaterra (Copa do Mundo de 1986, no México) ou a cobrança de falta de Ronaldinho Gaúcho contra Inglaterra (Copa do Mundo de 2002, na CoréiaJapão), emerge o seguinte questionamento: que fatores contribuem para esse rendimento excepcional? É consenso hoje no Treinamento Esportivo, tanto no meio acadêmico quanto no meio profissional, que o rendimento do atleta depende da interação das capacidades físicas, técnicas, táticas, psicológicas, biotipológicas e sócio-ambientais.

Dentro deste contexto, os estudos das capacidades táticas vêm despertando, particularmente nos últimos 10 anos, crescente interesse dos pesquisadores. Nos Jogos Esportivos Coletivos (JEC), as capacidades táticas ganham em significado. A elevada imprevisibilidade, aleatoriedade e variabilidade que compõem o contexto deste grupo de jogos solicitam de forma constante um comportamento tático dos participantes $(6,7,8,9,10)$.

Para Garganta(7), JEC é uma designação que engloba, entre outros, esportes tradicionais como

Basquetebol, Handebol, Futebol, Futsal e Voleibol, e ocupam um lugar de destaque na cultura esportiva contemporânea.

Nestas modalidades esportivas, para que o atleta tenha um bom desempenho durante os jogos, é necessário que o mesmo tenha conhecimento sobre a modalidade que pratica.

Chi e Glaser(4) afirmam que o conhecimento processual verifica-se na ação motora em si, que solicita a utilização de processos cognitivos necessários à execução da mesma.

Segundo Queiroga(20), o conhecimento processual pode ser definido como o conhecimento de "como fazer as coisas". De acordo com o autor, o mesmo é utilizado na ação motora em si, selecionando as técnicas adequadas à situação e executando-as.

De acordo com Eysenck e Keane (5), ao contrário do conhecimento declarativo que pode ser explicado, o conhecimento processual, geralmente, não pode ser formulado explicitamente.
McPherson(16) considera o conhecimento processual como um processo mais complexo em relação ao conhecimento declarativo, pois inclui, além da seleção da ação, a ação propriamente dita, ou seja, a realização do pensamento através de uma técnica ou de uma habilidade técnica.

O conhecimento processual, portanto, está diretamente relacionado com a execução de respostas para a resolução de problemas em situações de treino e jogo nos esportes coletivos. Considerando-se a característica imprevisível, aleatória e adaptativa desses jogos, torna-se indispensável um elevado nível de rendimento nesse tipo de conhecimento para se concretizar as respostas motoras adequadas as situações de jogo nessas modalidades esportivas $(2,6,8)$. Segundo Turner e Martinek ${ }^{(30)}$, alguns excelentes executantes de habilidades técnicas no desporto podem não conseguir operacionalizar a mesma, ou seja, utilizar a técnica de uma forma eficaz em situações de jogo, pois não sabem "como", "quando" e "onde" aplicar essas técnicas. Apresenta-se assim, uma falha seja na transferência do nível de conhecimento declarativo para o conhecimento processual, bem como da adequada utilização desse conhecimento, ou seja, um problema tático.

Sternberg(28) afirma que o conhecimento processual envolve um alto grau de habilidade motora que aumenta em conseqüência da prática, até que o desempenho e a realização da habilidade ou técnica necessite de pouca atenção consciente, ou seja, as respostas motoras passam a ser automáticas.

São poucos os estudos na literatura que tentaram analisar a variável conhecimento processual nos jogos esportivos coletivos. Isto se deve, em parte, à dificuldade de operacionalização desse construto, bem como a variabilidade das suas formas e conteúdos. Moreira(18) utilizou dois testes de conhecimento tático processual (CTP) para avaliar a capacidade tática de praticantes de Futsal da categoria sub-9, nos parâmetros "Oferecer-se e Orientar-se" e "Reconhecer Espaços" desenvolvidos e validados por Memmert(17). Esses testes oportunizam a avaliação do pensamento convergente e divergente que é aplicado em situação de jogo pelos participantes. Segundo Roth, Schörer e $\operatorname{Greco}^{(26)}$, apoiados em Guilford $(12,13)$ o pensamento convergente está ligado à inteligência do jogador e o pensamento divergente 
a criatividade tática. Os resultados observados neste estudo denotaram melhora nos dois parâmetros para os atletas que eram treinados com uma metodologia predominantemente global/situacional, ao passo que os atletas que eram treinados através de uma metodologia predominantemente analítica melhoraram em apenas um dos parâmetros (Oferecer-se e Orientar-se convergente).

No âmbito do Futebol, podem-se citar o estudo de Safont-Tria et al.(27), os quais realizaram a observação e análise do comportamento tático e da tomada de decisão de um jogador de futebol durante 4 jogos. Através dos resultados, os autores fizeram inferências sobre o CTP desse jogador em ações ofensivas. Já Helsen e Pauwels ${ }^{(14)}$ utilizaram um simulador de movimentos táticos (situações de jogo em vídeo, projetadas em filme numa parede, nas quais o voluntário responde e executa a decisão tática mais adequada com a bola) para verificar o conhecimento processual de 20 jogadores, sendo 10 que jogavam futebol de recreação e 10 praticantes federados com 10 anos de prática em competição. Os resultados demonstraram que os praticantes federados podem tomar decisões em maior quantidade, de forma mais rápida e no momento mais propício em relação aos praticantes de recreação.

Levando-se em consideração os aspectos abordados anteriormente, o objetivo do presente estudo foi responder às seguintes questões: O nível de CTP é maior quanto mais elevada for a categoria? Há diferenças de CTP considerando a posição específica ocupada pelo jogador no campo de jogo?

\section{MATERIAL E MÉTODOS}

A amostra voluntária deste estudo foi constituída por 221 jogadores de Futebol de campo do sexo masculino, sendo 80 da categoria sub-14, 69 da categoria sub-15 e 72 da categoria sub-17, todos pertencentes aos principais clubes da cidade de Belo Horizonte-MG, participantes de campeonatos em nível estadual, nacional e internacional.

Para avaliar o CTP dos jogadores foi utilizado o teste KORA (Avaliação Orientada através do Conceito dos Peritos), validado por Memmert ${ }^{(17)}$. A validação do teste para a língua portuguesa foi realizada através do procedimento de back translation (alemão-português-alemão) em relação aos elementos semânticos, mantendo-se o protocolo conforme o teste original. O teste KORA, utilizado neste estudo, oportuniza analisar a capacidade tática no parâmetro Oferecer-se e Orientar-se (KORA:O.O.).

Kröger e Roth ${ }^{(15)}$ conceituam o parâmetro Oferecerse e Orientar-se, inerente ao conjunto de elementos que constituem as denominadas capacidades táticas, como "tarefas táticas em que o importante é, no momento exato, obter uma posição ótima". Esse parâmetro está relacionado, portanto, com a capacidade de o jogador movimentar-se pelos espaços do campo, sempre procurando estar em uma linha de passe para receber a bola.

No Futebol, essa capacidade é fundamental para concretizar o jogo, pois os jogadores sem bola devem a todo instante procurar posições no campo nas quais possam receber a bola de um companheiro, a fim de possibilitar a seqüência do mesmo: transportar a bola para o objetivo, conseguir o espaço necessário para quando receber a bola, definir a situação. No teste foi estabelecida uma pontuação para as ações que o atleta realiza, de acordo com os conceitos propostos pelos peritos, os quais apresentaram uma consistência interna (Alfa de Cronbach) de 0,98 indicando a fidedignidade da avaliação na aplicação do instrumento. Para obter-se a consistência interna entre os observadores desse estudo, também foi utilizado o coeficiente Alfa de Cronbach.

A Tabela 1 mostra os valores obtidos no procedimento de analise de consistência interna (Alpha de Cronbach) entre os avaliadores do presente trabalho, em cada categoria analisada.

Tabela 1. Consistência interna entre os avaliadores por categoria

\begin{tabular}{|c|c|c|}
\hline Categoria & & \\
\hline & Convergente & Divergente \\
\hline Sub-14 & $0,92 *$ & $0,86^{*}$ \\
\hline Sub-15 & $0,86^{*}$ & $0,79 *$ \\
\hline Sub-17 & $0,90 *$ & $0,85^{*}$ \\
\hline
\end{tabular}

Observa-se na Tabela 1 que todos os valores são maiores do que o valor mínimo considerado na literatura como aceitável para configurar que há consistência entre os avaliadores $(3,19,29)$. 
Tabela 2. Grelha de avaliação do CTP (convergente).

Qualidade da solução /
Se oferecer se orientar
Procurar a posição adequada
para receber a bola
Ótimo

Sempre Livre

\section{Ótimo}

Sempre Livre

\section{Muito bom}

Quase Sempre

\section{Muito bom}

Quase Sempre

Bom
Freqüentemente

\section{Suficiente}

Alternadamente

\section{Pobre}

Quase Nunca

\section{Pobre \\ Quase Nunca}

\section{Insuficiente}

Nunca

\section{Insuficiente}

Nunca

\begin{tabular}{c}
\hline $\begin{array}{c}\text { Nível de } \\
\text { definição } \\
\text { da situação }\end{array}$ \\
\hline DIFÍCIL
\end{tabular}

10

10 sempre uma boa posição para dar a quem tem a bola opção de passe.

FÁCIL

DIFÍCIL

FÁCIL

DIFÍCIL

FÁCIL

DIFÍCIL

FÁCIL

DIFÍCIL

FÁCIL

(1)

\section{Pontos Exemplo}

0 jogador tem, procurado sempre a posição ótima e oferecido ao colega a possibilidade de passe. No entanto, a situação não era tão difícil.

80 jogador tem apesar de estar em uma situação difícil procurado quase sempre achar a posição ótima para que seu colega em posse de bola efetue o passe.

0 jogador tem procurado quase sempre a posição ótima para que o colega em posse de bola tenha a opção de passe no entanto a situação não era muito difícil.

$6 \quad 0$ jogador apesar de estar em uma posição difícil tem procurado freqüentemente uma posição ótima para dar a possibilidade de passe.

O jogador tem de forma irregular procurado a posição ótima e oferecido ao portador da bola quase sempre a possibilidade de passe. A situação não era difícil.

40 jogador não tem quase nunca procurado a posição ótima de forma a oferecer ao portador da bola a opção de passe, no entanto a situação de jogo era difícil.

30 jogador apesar de estar em uma situação fácil não tem procurado quase nunca uma posição ótima para oferecer ao colega portador da bola a opção de passe.

20 jogador não tem procurado quase nunca a posição ótima para oferecer ao colega (portador da bola) a opção de passe. No entanto, era uma situação difícil.

10 jogador apesar de estar em uma situação fácil não tem procurado nunca uma ótima posição para oferecer ao colega a opção de passe.
Para a realização do teste de CTP (KORA:O.O.) os praticantes são divididos em dois grupos de três jogadores cada, com coletes numerados de 1 a 6 . Cada grupo possui um colete com uma cor diferente, sendo numerados de 1 a 3 para uma cor e de 4 a 6 para outra, com objetivo de facilitar a identificação dos jogadores por parte dos peritos. O teste consiste na filmagem das ações dos sujeitos que realizam um jogo com estruturação tática de 3 x 3 com marcação individual, num quadrado de 9 metros em cada lado, jogando com os pés e com objetivo de manter a posse de bola, sendo a movimentação livre dentro da área demarcada. Os 
Tabela 3. Grelha de avaliação do CTP [divergente]

\begin{tabular}{l} 
Originalidade da Solução \\
na Situação de jogo \\
(uso do espaço ou passe) \\
\hline Amplo acima da media \\
(muito original)
\end{tabular}

Amplo acima da média
[original]

\begin{tabular}{l}
\hline Acima da média \\
[quase sempre] \\
\hline Bom, na média \\
(algumas vezes] \\
\hline Na média \\
(ainda faz coisas novas] \\
\hline Suficiente, ainda \\
(consegue coisas novas] \\
\hline Pobre, próximo da média \\
(com poucas coisas novas] \\
\hline (quase somente padrão] \\
\hline (próximo do padrão] \\
\hline Pobre, abaixo da média \\
\hline
\end{tabular}

\begin{tabular}{c}
\hline $\begin{array}{c}\text { Flexibilidade } \\
\text { nas soluções das } \\
\text { situações de jogo }\end{array}$ \\
\hline Duas ou mais \\
(ações originais)
\end{tabular}

Duas ou mais

(ações originais)

\begin{tabular}{c}
$\begin{array}{c}\text { Duas ações } \\
\text { (originais, raridade que } \\
\text { não aparecem de forma } \\
\text { pouco freqüente) }\end{array}$ \\
\hline $\begin{array}{c}\text { Duas ações novas } \\
\text { (que aparecem de } \\
\text { forma pouco freqüente) }\end{array}$ \\
\hline $\begin{array}{c}\text { Duas ações } \\
\text { (pouco freqüentes) }\end{array}$ \\
Uma \\
(Ação pouco freqüente) \\
Uma
\end{tabular}

\section{Pontos Exemplo}

$10 \quad 0$ jogador mostra diferentes soluções originais, pouco comuns ou pouco conhecidas / esperadas várias vezes para resolver a situação. As procuras temporais de ótimas posições foram sempre (completamente) excelentes.

90 jogador mostra diferentes soluções originais / fora do comum, ou pouco conhecidas. As procuras temporais de ótimas posições foram sempre muito boas.

$8 \quad 0$ jogador mostra duas diferentes soluções que não foram originais / fora do comum, mas que aparecem de forma esporádica. As procuras temporais de ótimas posições foram sempre surpresas.

? 0 jogador mostra duas diferentes soluções que não foram originais, mas que aparecem de forma esporádica. As procuras temporais de ótimas posições foram sempre surpresas.

60 jogador mostra uma diferente solução que não são dentro do repertório Padrão, mas que já apareceram. As procuras temporais de ótimas posições tiveram sim novidade.

50 jogador mostra uma diferente solução que não são dentro do repertório Padrão, mas que aparecem freqüentemente. As procuras temporais de ótimas posições tiveram sim ainda uma novidade.

$4 \quad 0$ jogador apesar de estar em uma situação fácil não tem procurado quase nunca uma posição ótima para oferecer ao colega portador da bola a opção de passe. 0 jogador não tem procurado quase nunca a posição ótima para oferecer ao colega (portador da bola] a opção de passe. No entanto, era uma situação difícil.

Nenhuma $\quad 30$ jogador mostra em regra gerais soluções, dentro do repertório Padrão, que aparecem freqüentemente. Ocasionalmente as procuras temporais de ótimas posições tiveram um pouco de novidade.

Nenhuma 2 jogador mostra quase somente soluções dentro do repertório Padrão, que aparecem sempre. Muito ocasionalmente as procuras temporais de ótimas posições tiveram um pouco de novidade.

Nenhuma 1 jogador mostra somente soluções Padrão, que aparecem sempre. As procuras temporais de ótimas posições não tiveram novidade. defensores não podem tirar a bola que está dominada pelo atacante, devendo manter uma distância de aproximadamente um metro do jogador em posse da mesma. Os defensores podem, sim, antecipar e inter- ceptar passes, somente não podem abordar o jogador em posse de bola em situações de 1 x 1 , para o desarme, adotando somente uma atitude de pressão do atacante em posse de bola a distância. 
As ações táticas da equipe (3 jogadores), são filmadas por 3 minutos, para cada grupo. Conforme estipulado no protocolo de Memmert(17), procede-se a troca de funções ataque-defesa entre os grupos cada vez que transcorrem os 3 minutos. No protocolo, toda vez que a bola for interceptada pela equipe que estiver com a função de defesa, o jogo deverá ser interrompido, sendo reiniciado no centro, numa área demarcada especificamente.

As ações táticas realizadas pelos praticantes durante o jogo são gravadas em imagens de vídeo e avaliadas por três peritos treinados especificamente para realizar esta tarefa. O processo de avaliação apóia-se no critério estabelecido por Memmert(17), que apresenta uma escala de pontuação que varia entre 0 a 10 pontos. O critério a ser avaliado é a procura adequada de posições no espaço livre de marcação: o jogador está livre para receber? Isso significa que o aluno que não está de posse da bola é que está sendo avaliado.

Procura-se analisar o comportamento e as ações do jogador sem bola, na sua capacidade de ser ponto de apoio para o colega que recebe a marcação.

Os peritos avaliam o desempenho dos sujeitos, estabelecem os pontos de acordo com as ações táticas realizadas no quesito Oferecer-se e Orientar-se, seguindo as grelhas de avaliação (Tabelas 2 e 3 ), analisando as formas subjacentes de pensamento convergente e divergente, na ação tática executada. Para esse procedimento, os peritos assistem a fita do teste em dois momentos distintos, um para analisar o pensamento convergente e outro para analisar o pensamento divergente subjacente à ação realizada pelo jogador.

Foi garantido, tanto aos clubes convidados quanto aos inquiridos, o anonimato e a confidencialidade dos dados.

\section{Tratamento Estatístico}

Considerando que a amostra não obedece a uma distribuição normal e que a avaliação do CTP é medida por uma escala ordinal, utilizou-se o seguinte tratamento estatístico:

- Para a descrição das características dos sujeitos desta amostra utilizou-se a estatística descritiva; - Kruskal-Wallis para diferenças de CTP entre as três categorias, com Mann-Whitney para identificar onde se encontram as diferenças;
— Kruskal-Wallis para diferenças de CTP entre as posições específicas ocupadas no campo de jogo, com Mann-Whitney para identificar onde encontramse as diferenças;

- Alpha de Conbrach para consistência interna entre avaliadores;

— O nível de significância foi mantido em $p \leq 0,05$.

\section{APRESENTAÇÃO E DISCUSSÃO DOS RESULTADOS Comparação do nível de CTP (convergente) com a categoria}

Esse estudo objetivou avaliar o nível de CTP de jogadores de Futebol, comparando os escores obtidos em função da categoria a que o jogador pertence e à posição que o mesmo ocupa no campo de jogo. $\mathrm{Na}$ Tabela 4 estão registrados os valores correspondentes aos dados descritivos para o teste de CTP (KORA:O.O-convergente).

Tabela 4. Dados descritivos do CTP [convergente] por categoria

\begin{tabular}{lccccc}
\hline & N & Média & Mediana & Moda & Desvio padrão \\
\hline Sub-14 & 80 & 4,08 & 4 & 4 & 1,04 \\
Sub-15 & 69 & 5,50 & 5 & 5 &, 98 \\
Sub-17 & 72 & 6,34 & 6 & 6 & 1,17 \\
Geral & 221 & 5,26 & 5 & 5 & 1,43 \\
\hline
\end{tabular}

Na Tabela 4, verifica-se que há diferenças nas médias dos escores obtidos pelas 3 categorias em estudo, sendo a média da categoria sub-17 $(6,34)$ a maior de todas, seguida pela média da categoria sub-15 $(5,50)$ e da categoria sub-14 $(4,08)$.

Observando os valores da média, mediana e moda e recorrendo à escala da avaliação do teste de conhecimento tático processual (KORA: O.O.-convergente), pode-se descrever como caracterizam-se a maioria dos jogadores de cada categoria em relação ao CTP (convergente).

$\mathrm{Na}$ categoria sub-14 os valores de medida de tendência central apontam como característica predominante: " $O$ jogador não tem quase nunca procurado a posição ótima de forma a oferecer ao portador da bola a opção de passe".

$\mathrm{Na}$ categoria sub-15 os valores de medida de tendência central registram o comportamento tático: "O jogador tem de forma irregular procurado a posição ótima e oferecido ao portador da bola quase sempre a possibilidade de passe". 
Já na categoria sub-17 os valores de medida de tendência central caracterizam o comportamento tático: "O jogador apesar de estar em uma posição difícil tem procurado freqüentemente uma posição ótima para dar a possibilidade de passe".

Aplicando-se o teste não-paramétrico de KruskalWallis verificou-se que há diferenças significativas entre os grupos $(\mathrm{p}<0,001)$. Para verificar, porém, onde encontram-se essas diferenças aplicou-se o teste de Mann-Whitney (Tabela 5).

Tabela 5. Comparação do nível de CTP (convergente) com a categoria através do teste de Mann-Whitney

\begin{tabular}{lccc}
\hline Categoria & Média dos Ranks & Soma dos Ranks & Sig. \\
\hline Sub-14 & 50,99 & 4079,00 &, $000^{*}$ \\
Sub-15 & 102,84 & 7096,00 & \\
Sub-14 & 47,06 & 3765,00 &, $000^{*}$ \\
Sub-17 & 109,21 & 7863,00 & \\
Sub-15 & 53,84 & 3715,00 &, $000^{*}$ \\
Sub-17 & 87,44 & 6296,00 & \\
\hline
\end{tabular}

* diferenças estatisticamente significativas para $p \leq 0,05$

Na Tabela 5 visualiza-se que houve diferenças significativas entre todas as categorias estudadas, ou seja, para a amostra em questão, os jogadores da categoria sub-17 possuem um nível de CTP (convergente) significativamente maior do que os jogadores sub-15 e sub-14. Os jogadores sub-15, por sua vez, possuem um CTP (convergente) maior que os jogadores da sub-14.

Como afirma Anderson(1), quando se aprende algo, isso é aprendido e codificado de forma declarativa, mas com o treino se torna compilado numa forma processual de conhecimento, a qual segundo Greco(9) passa a ser utilizada nas ações de forma automatizada, oportunizando ações antecipativas, já que a atenção pode estar direcionada a outros aspectos da situação do que a própria realização da ação. Como relatou-se anteriormente, o pensamento convergente, que se caracteriza pela escolha de uma resposta ideal perante situações que apresentam uma relativa hierarquia de alternativas de escolha para solução de um problema, está intimamente ligado com a inteligência de jogo, isto é, escolha de soluções adequadas a situação que o jogo apresenta.
Comparação do nível de CTP (convergente) com a posição Foi objetivo do estudo, além de comparar o nível de CTP (convergente) em função da categoria a qual o atleta pertence, verificar se há diferenças de CTP (convergente) em relação à posição ocupada pelo jogador no campo de jogo.

A Tabela 6 traz os dados descritivos do CTP (convergente) dos jogadores por posição.

Tabela 6. Dados descritivos do CTP (convergente) por posição.

\begin{tabular}{lccc}
\hline Posição & $\mathrm{n}$ & Média & Desvio padrão \\
\hline Goleiro & 25 & 3,61 &, 76 \\
Lateral/ala & 37 & 5,34 & 1,40 \\
Zagueiro & 37 & 5,29 & 1,19 \\
Volante & 40 & 5,32 & 1,42 \\
Meia & 43 & 5,78 & 1,37 \\
Atacante & 39 & 5,58 & 1,35 \\
Geral & 221 & 5,26 & 1,43 \\
\hline
\end{tabular}

Na Tabela 6 observa-se que os jogadores na função de meia foram os jogadores com a média mais alta de resposta $(5,78)$ no teste de CTP (convergente), seguidos pelos atacantes $(5,58)$. Já os goleiros foram os atletas que obtiveram a média mais baixa $(3,61)$ no referido teste, o que pode se compreender pela especificidade da sua função no jogo.

Para uma melhor explicação sobre esses resultados específicos recorreu-se ao teste não-paramétrico Kruskal-Wallis, com Mann-Whitney para verificar em quais posições apresentavam-se diferenças de CTP (convergente), cujos resultados podem ser visualizados na Tabela 7.

Através do teste de Kruskal-Wallis comprovou-se que há diferenças significativas $(\mathrm{p}<0,001)$ de CTP (convergente) conforme as posições que os atletas ocupam no campo de jogo, porém no momento que utilizou-se para a o teste de Mann-Whitney (Tabela 7), a fim de averiguar onde encontravam-se essas diferenças, verificou-se, através dos valores de $p$, que apenas os goleiros obtiveram escores estatisticamente diferentes em relação às outras posições.

Esse resultado pode ser explicado através da especificidade do teste, pois trata-se de analisar a aplicação do conhecimento processual em situação muito próxima da característica real do jogo, ao qual o goleiro não está 
Tabela 7. Comparação do nível de CTP (convergente) por posições através do teste de Mann-Whitney

\begin{tabular}{|c|c|c|c|c|c|c|}
\hline & Goleiros & Laterais/alas & Zagueiros & Volantes & Meias & Atacantes \\
\hline Goleiros & - & ,000* & ,000* & ,000* & ,000* & ,000* \\
\hline Laterais/alas & ,000* & - & ,952 & ,963 & 177, - & 383 \\
\hline Zagueiros & ,000* & ,952 & - &, 967 & ,096 & ,297 \\
\hline Volantes &, $000^{*}$ & ,963 & ,967 & - & ,140 & ,381 \\
\hline Meias & ,000* & 177 & ,096 & 140 & - & ,532 \\
\hline Atacantes & ,000* & ,383 & 297 & ,381 & ,532 & - \\
\hline
\end{tabular}

* diferenças estatisticamente significativas para $p \leq 0,05$

familiarizado, portanto o jogo com os pés para este atleta tem uma limitação em relação a sua aplicação. Pode-se inferir, portanto, que não houve diferenças significativas de CTP (convergente) em função da posição ocupada pelos jogadores no campo, com exceção da posição de goleiro.

Comparação do nível de CTP (divergente) com a categoria Foi também objetivo do estudo verificar o nível de CTP (divergente), considerando que essa forma de manifestação do pensamento é extremamente importante para o comportamento tático, na medida em que está estritamente relacionada com a criatividade tática dos atletas (26, 21, 22, 23, 24, 25).

A Tabela 8 mostra os dados descritivos do CTP (divergente) dos jogadores, em função da categoria.

Tabela 8. Dados descritivos do CTP [divergente] por categoria.

\begin{tabular}{lccccc}
\hline & N & Média & Mediana & Moda & Desvio padrão \\
\hline Sub-14 & 80 & 2,43 & 2 & 2 &, 83 \\
Sub-15 & 69 & 3,46 & 3 & 3 &, 92 \\
Sub-17 & 72 & 4,18 & 4 & 4 & 1,04 \\
Geral & 221 & 3,32 & 3 & 3 & 1,18 \\
\hline
\end{tabular}

Na Tabela 8, verifica-se que há diferenças nas médias dos escores obtidos pelas 3 categorias em estudo, sendo a média da categoria sub-17 $(4,18)$ a maior de todas, seguida pela média da categoria sub-15 $(3,46)$ e da categoria sub-14 $(2,43)$.
Observando os valores da média, mediana e moda e recorrendo à escala da avaliação do teste, pode-se descrever como caracterizam-se a maioria dos jogadores de cada categoria em relação ao CTP (divergente). $\mathrm{Na}$ categoria sub-14 os valores de medida de tendência central apontam como característica predominante: "O jogador mostra quase somente soluções dentro do repertório padrão, que aparecem sempre. Muito ocasionalmente as procuras temporais de ótimas posições tiveram um pouco de novidade".

$\mathrm{Na}$ categoria sub-15 os valores de medida de tendência central registram o comportamento tático dos atletas: "O jogador mostra, em regra gerais, soluções dentro do repertório padrão, que aparecem freqüentemente. Ocasionalmente as procuras temporais de ótimas posições tiveram um pouco de novidade".

Já na categoria sub-17 os valores de medida de tendência central levam à seguinte característica na escala: "O jogador mostra uma diferente solução que não está dentro do repertório padrão, mas que aparece freqüentemente. As procuras temporais de ótimas posições tiveram sim ainda uma novidade".

Para descobrir, porém, se essas diferenças descritivas confirmavam-se estatisticamente, foi aplicado o teste não-paramétrico Kruskal-Wallis, no qual verificou-se que há diferenças significativas entre os grupos $(p<0,001)$. Ainda, não se registra onde se encontram essas diferenças, para tanto, aplicou-se o teste de Mann-Whitney (Tabela 9). 
Tabela 9. Comparação do nível de CTP [divergente] com a categoria através do teste de Mann-Whitney

\begin{tabular}{lccc}
\hline Categoria & Média dos Ranks & Soma dos Ranks & Sig. \\
\hline Sub-14 & 54,01 & 4320,50 &, $000^{*}$ \\
Sub-15 & 99,34 & 6854,50 & \\
Sub-14 & 48,02 & 3841,50 &, $000^{*}$ \\
Sub-17 & 108,15 & 7786,50 & \\
Sub-15 & 55,31 & 3816,50 &, $000^{*}$ \\
Sub-17 & 86,03 & 6194,50 & \\
\hline
\end{tabular}

* diferenças estatisticamente significativas para $p \leq 0,05$

Através da Tabela 9, verifica-se que houve diferenças significativas para as 3 categorias em estudo, sendo a categoria sub-17 com um maior nível de CTP (divergente) em relação às categorias sub-15 e sub-14 e a categoria sub-15 com um maior nível de CTP (divergente) em comparação à categoria sub-14.

Levando-se em consideração que o pensamento divergente forma a base para a criatividade dos jogadores $(26,21,22,23,24,25)$, os resultados acima sugerem que quanto mais elevada a categoria, maior a criatividade tática do atleta.

Reportando-se, porém, aos resultados dos escores obtidos pelos atletas nos dados descritivos (ver Tabela 6), em relação aos aspectos divergentes do pensamento, concluí-se que esses escores foram muito baixos.

Esse fato pode ser elucidado, em parte, por um problema já exposto por alguns autores $(7,10,26)$ em relação ao treinamento da criatividade nos jogos esportivos coletivos.

Apesar de não terem sido analisadas as sessões de treinos das equipes que compõem a amostra desse estudo, justificada pela inviabilidade operacional em função da falta de consentimento dos treinadores para realização de filmagens, não se pode afirmar categoricamente que o desenvolvimento da criatividade vem sendo negligenciado nas sessões de treinamento dessas equipes.

Ao considerar, porém, os escores obtidos pelos jogadores no teste, esse fato levanta dúvidas em relação à eficiência dos processos de ensino-aprendizagemtreinamento aplicados nas categorias de base. Roth, Schörer e Greco(26) ponderam, porém, que apesar de ser indiscutível a importância do desenvol- vimento da criatividade, observa-se uma relativa falta de recomendações e sugestões para a elaboração de processos de ensino-aprendizagem-treinamento nos jogos esportivos coletivos direcionados a essa finalidade.

Comparação do nível de CTP (divergente) com a posição Neste estudo objetivou-se também comparar o nível de CTP (divergente) em função da categoria a qual o atleta pertence, bem como verificar se há diferenças de CTP (divergente) em relação à posição ocupada pelo jogador no campo de jogo.

A Tabela 10 traz os dados descritivos do nível de nível de rendimento CTP (divergente) dos jogadores por posição.

Tabela 10. Dados descritivos do nível de rendimento do CTP (divergente) por posição.

\begin{tabular}{lccc}
\hline Posição & $\mathbf{n}$ & Média & Desvio padrão \\
\hline Goleiro & 25 & 2,03 &, 61 \\
Lateral/ala & 37 & 3,42 & 1,22 \\
Zagueiro & 37 & 3,24 &, 87 \\
Volante & 40 & 3,33 & 1,15 \\
Meia & 43 & 3,79 & 1,15 \\
Atacante & 39 & 3,62 & 1,20 \\
Geral & 221 & 3,32 & 1,18 \\
\hline
\end{tabular}

Na Tabela 10 observa-se que os meias foram os jogadores com os valores mais altos na média $(3,79)$ no teste de CTP (KORA:OO-divergente), seguidos pelos atacantes $(3,62)$. Já os goleiros foram os atletas que obtiveram a média mais baixa $(2,03)$ no referido teste. Para uma melhor explicação sobre esses resultados específicos recorremos ao teste de Kruskal-Wallis, com Mann-Whitney para identificar onde encontramse as possíveis diferenças. Os resultados encontrados podem ser visualizados na Tabelas 11 .

Na Tabela 11 verificou-se que os goleiros obtiveram escores estatisticamente diferentes em relação a todas as outras posições e que os escores obtidos pelos meias foram estatisticamente diferentes em relação aos zagueiros.

Já abordou-se anteriormente que esse resultado específico dos goleiros possivelmente tenha ocorrido devido às diferenças de característica da posição de goleiro para com as demais posições. 
Tabela 11. Comparação do nível de CTP (divergente) por posições através do teste de Mann-Whitney

\begin{tabular}{lcccccc}
\hline & Goleiros & Laterais/alas & Zagueiros & Volantes & Meias & Atacantes \\
\hline Goleiros & - &, $000^{*}$ &, $000^{*}$ &, $000^{*}$ &, $000^{*}$ &, $000^{*}$ \\
\hline Laterais/alas &, $000^{*}$ & - &, 640 &, 886 &, 153 &, 381 \\
\hline Zagueiros &, $000^{*}$ &, 640 & - &, 922 &, $033^{*}$ &, 123 \\
\hline Volantes &, $000^{*}$ &, 886 &, 922 & - &, 094 &, 306 \\
\hline Meias &, $000^{*}$ &, 153 &, $033^{*}$ &, 094 & - &, 631 \\
\hline Atacantes &, $000^{*}$ &, 381 &, 123 &, 306 &, 631 & -
\end{tabular}

* diferenças estatisticamente significativas para $p \leq 0,05$

Já em relação às diferenças entre os jogadores da função de meias e os zagueiros, pode-se inferir que, devido ao conhecimento tático processual divergente estar estritamente relacionado com a criatividade dos jogadores, os meias podem ter esse tipo de conhecimento mais desenvolvido, pois jogam em uma zona do campo na qual necessitam de criatividade para dar seqüência às jogadas. Já os zagueiros jogam em uma "zona de risco", na qual geralmente a simplificação da jogada apresenta-se como mais adequada, sendo, portanto, escassos os momentos em que utiliza-se da manifestação do pensamento divergente.

\section{CONCLUSÕES}

A partir dos resultados apresentados e discutidos anteriormente e relacionando-os com as questões de estudo desse trabalho, chegou-se às seguintes conclusões:

Em relação à primeira questão de estudo: o nível de CTP é maior quanto mais elevada for a categoria? Verificou-se que, tanto na manifestação do pensamento convergente quanto divergente, os atletas da categoria sub-17 obtiveram melhores resultados em relação às categorias sub-15 e sub-14. Já os jogadores da categoria sub-15, por sua vez, alcançaram melhores escores que os seus pares da categoria sub- 14 . Já em relação à segunda questão de estudo: há diferenças de CTP considerando a posição específica ocupada pelo jogador no campo de jogo? Verificou-se que, em relação à manifestação do pensamento convergente (inteligência de jogo), as diferenças apre- sentadas foram apenas dos goleiros para com todas as outras posições. Já em relação à manifestação do pensamento divergente, que está mais relacionado com a criatividade tática $(11,12,13)$, além das diferenças dos goleiros para com todas as outras posições, foram encontradas também diferenças significativas entre zagueiros e meias.

\section{CORRESPONDÊNCIA}

Diogo Schüler Giacomini

Rua Desembargador Paula Mota, 30, apto.302

Bairro Ouro Preto, CEP: 31310-340

Belo Horizonte-MG, Brasil

E-mail: diogogiacomini@pop.com.br 


\section{REFERÊNCIAS}

1. Anderson JR (1983). The architecture of cognition. Harvard: Harvard Univesity Press.

2. Araújo D (1999). Tomada de decisão dinâmica: níveis de expertise em vela e controlo de situações simuladas. Dissertação de Mestrado em Psicologia do Desporto. Universidade Técnica de Lisboa: FMH.

3. Barros M, Reis R (2003). Análise de dados em atividade física e saúde: demonstrando a utilização do SPSS. Londrina: Editora Midiograf.

4. Chi M, Glaser R (1980). The measurement of expertise: analysis of the development of knowledge and skill as a basis for assessing achievement. Educational Testing an Evaluation. Beverly Hills. Sage, p. 37-47.

5. Eysenck M, Keane M (1994). Psicologia Cognitiva: um manual introdutório. Porto Alegre: Artes Médicas Editora.

6. Garganta J (1997). Modelação táctica do jogo de futebol - estudo da organização da fase ofensiva em equipas de alto rendimento. Tese de Doutorado. FCDEF. Universidade do Porto.

7. Garganta J (2002). Competências no ensino e treino de jovens futebolistas. EF Deportes Revista Digital. Buenos Aires, Ano 8, Fevereiro, $n^{\circ} 45$. www.efdeportes.com

8. Graça, A (1994). Os comos e os quandos no ensino dos jogos. Em O Ensino dos Jogos Desportivos. A. Graça. e J. Oliveira (Eds). CEJD, FCDEF. Universidade do Porto, p.27-46.

9. Greco P (2006). Conhecimento tático-técnico: eixo pendular da ação tática (criativa) nos jogos esportivos coletivos. Revista Brasileira de Educação Física e Esporte. São Paulo, 20, 210-212.

10. Greco, PJ, Benda RN (1998). Iniciação Esportiva Universal: da aprendizagem motora ao treinamento técnico. Volume 1. Belo Horizonte: Editora UFMG.

11. Guilford J (1950). Creativity. American Psychologist, 5, 444454.

12. Guilford J (1956). Structure of intellect. Psychological Bulletin, 53, 267-293.

13. Guilford J (1967). The nature of human intelligence. New York, Mc Graw-Hill.

14. Helsen W, Pauwels J (1987). The use of a simulator in evaluation and training of tactical skills. In: Soccer Instituut voor Lichamelijke Opleiding, p. 13-17. Bélgica.

15. Kröger C, Roth K (2002). Escola da bola: um ABC para iniciantes nos jogos esportivos. São Paulo: Phorte.

16. McPherson S (1999). Tactical differences in problem representations and solutions in collegiate varsity and beginner female Tennis players. Research Quarterly and Sport. 7 (4), 369-384.

17. Memmert D (2002). Diagnostik Taktischer Leistungskomponenten: Spieltestsituationen und Konzeptorientierte Expertenratings. Tese de Doutorado. Universidade de Heidelberg, Alemanha.

18. Moreira V (2005). A influencia de processos metodológicos de ensino-aprendizagem-treinamento (E-A-T) na aquisição do conhecimento tático no futsal. Dissertação de Mestrado. Belo Horizonte: Escola de Educação Física, Fisioterapia e Terapia Ocupacional da Universidade Federal de Minas Gerais.

19. Pasquali L (1996). Teoria e métodos de medida em ciências do comportamento. Laboratório de Pesquisa em Avaliação e Medida/Instituto de Psicologia. Universidade de Brasília.

20. Queiroga M (2005). O conhecimento táctico-estratégico do dis- tribuidor de alto nível: um estudo com distribuidores das selecções brasileiras de voleibol feminino e masculino. Dissertação de Mestrado. Universidade do Porto, FCDEF.

21. Raab M (2002). T-ECHO: Model of decision making to explain behaviour in experiments and simulations under time pressure. Psychology of Sport and Exercise, 3(2), $151-171$.

22. Raab M (2003). Decision making in sport: influence of complexity on implicit and explicit learning. International Journal of Sport and Exercise Psychology, 1, 406-433.

23. Roth K (1989). Taktik im Sportspiel. Band 69. Bundes Institut für Sport und Sportwissenschaft. Schorndorf. R.F. Alemanha, Hofmann.

24. Roth K (1990). Externe Validität und Problemkomplexität. Sportwissenschaft. Schorndorf. R.F. Alemanha, Hofmann. 20 (3), 281-299.

25. Roth K (1991). Entscheidungsverhalten im Sportspiel. Sportwissenschaft. Schorndorf. R.F. Alemanha, Hofmann. 21, (3), 229-246.

26. Roth K, Schörer J, Greco P (2004). Ein kleines $3 \times 3$ zur Kreativitätsentwicklung im Handball. Praktische Trainingsbeispiele für die früzeitige Ausbildung einer kreativen Handlungsfähigkeit. Volume 4, p. 2-6.

27. Safont-Tria B, Riera J, Traver V, Nicolau J (1996). Propuesta de análisis de la táctica individual ofensiva en el fútbol. Apunts: Educación Física $i$ Esportes, 63-71.

28. Sternberg RJ (2000). Psicologia Cognitiva. Porto Alegre: Artemed.

29. Thomas JR, Nelson JK (2002). Métodos de Pesquisa em Atividade Física. Editora Artmed. $3^{\mathrm{a}}$ ed. Porto Alegre.

30. Turner A, Martinek T (1995). Teaching for understanding: a model for improving decision making during game play. Quest, 44, 44-63. 